\title{
Incorporating innovative water management science and technology into water management policy
}

\author{
Mark F. Colosimo' ${ }^{1}$ Hyunook Kim $^{2}$ (1) \\ ${ }^{1}$ International Joint Commission, 1250 23rd St NW, Suite 100, Washington, DC 20037, USA \\ ${ }^{2}$ Department of Environmental Engineering, University of Seoul, 90 Jeonnong-dong, Seoul 130-743, Korea
}

Received: 28 January 2016/Revised: 12 February 2016/Accepted: 14 February 2016/Published online: 25 February 2016 (C) Joint Center on Global Change and Earth System Science of the University of Maryland and Beijing Normal University and Springer-Verlag Berlin Heidelberg 2016

\begin{abstract}
Water is a unique and limited resource. An ample supply of good quality water is a concern, and the potential for water shortages exist. Such shortages of good quality water are real and would likely have significant impacts on the economy and the environment. In the USA, the public expects water management science and technology to be incorporated into effective polices to help minimize or offset adverse impacts on water. Such integration takes time and challenges exist. Challenges to such integration include the need to educate decision makers, lack of needed incentives, limited benefit quantification methods, uncertainty in measurement or estimation of technology performance, the need for comprehensive guiding principles such as sustainability, and lack of broadscale application of techniques such as adaptive management and environmental management systems. There is a compelling need to continuously make advances in the water management science and technology arena to meet these challenges; however, there is a commensurate need to educate decision makers and stakeholders about the potential benefits derived by the application of such advances. Such educational efforts are needed to better integrate science, technology and water policy in order to make better use of available water.
\end{abstract}

Keywords Water quality management - Water science and technology $\cdot$ System integration

We appreciate financial support from Korea Environmental Industry \& Technology Institute (Project No: 2015001790002).

Hyunook Kim

h_kim@uos.ac.kr

\section{Introduction}

Water courses, such as rivers and streams, drain the land in a watershed. In relatively undisturbed watersheds or more natural watersheds, infiltration is maximized and natural buffers limit overland flow, filter nutrients, and stabilize stream banks. Under these more natural conditions, nutrient use is facilitated by trapping nitrogen and phosphorus compounds, effectively incorporating nutrients into biomass, and providing a stable, well-filtered water supply to lakes and streams. Land-use changes from forested to either urban or agricultural uses disturb these natural processes, typically causing an increase in overland flow that exports nutrients and sediment to surface water, a decrease in the rate of groundwater recharge, and an increase in soil erosion rates. Erosion contributes to removal of nutrients, soil organic matter, and fine particles. Harmful consequences of farm production on water quality include soil erosion; runoff into rivers and streams of fertilizers; animal waste, and pesticides; and leaching into groundwater of nutrients and pesticides (Ribaudo et al. 2013). As eroded soils enter rivers and streams, they degrade or destroy habitats. Generally, land-use changes from forested conditions result in adverse impacts on aquatic ecosystems. Adverse impacts on physical, biological, and chemical stream or river conditions are well documented. Studies conducted by the United States (US) Environmental Protection Agency (EPA) and the US Geologic Survey (USGS) have found that agriculture is a major contributor to pollution of US waters (United States Geological Survey 1999; United States Environmental Protection Agency 2003).

Water is a unique and limited resource. As the trend to convert forest to other types of land cover continues, clean 
water will only become more limited and will increase demand for clean water, as more use pressure is put on our waters. In turn, this will lead to increased competition among water use needs. The availability of an ample supply of good quality water is in serious doubt in some areas of the USA, however. A recent report by the General Accounting Office (2003), entitled, Freshwater Supply: States' View of How Federal Agencies Could Help Them Meet the Challenges of Expected Shortages indicates that demands on US water supplies are growing, yet storing capacity for surface water is limited, groundwater is being depleted, and pressures to keep water in-stream for fisheries and the environment exist. The potential for shortages of good quality water is real and would likely have significant impacts on the economy and the environment.

In the USA, the public expects water management science and technology to be incorporated into effective polices to help minimize or offset adverse impacts on water. However, it often takes a substantive amount of time and effort to incorporate technology into policy. The purpose of this paper is to explore actions necessary to more effectively facilitate the incorporation of new, innovative water management technologies (and science) into policies that benefit the environment and economy.

\section{US laws on water quality}

Many US federal laws deal with water quality. US water quality goals were established by the Federal Water Pollution Control Act and its amendments (33 U.S.C. 1251 et seq), commonly known as the Clean Water Act (United States Environmental Protection Agency 2003). The objective of the Clean Water Act is the restoration and maintenance of chemical, physical, and biological integrity of the nation's surface waters. Similar goals for groundwater were established by the Safe Drinking Water Act and its amendments (42 U.S.C $311 \mathrm{f}$ et seq.). These federal laws substantiate the national concern over water pollution and provide a number of US agencies with a role in water resources management; many US federal agencies have water resource-related responsibilities (General Accounting Office 2003).

Initial governmental water pollution control efforts were directed toward "point source" (pollution from well-defined and discrete sources) through extensive federal funding of the construction grants program for publicly owned treatment works. Effective control programs for point sources (PSs) have been developed based on treatment and controlled release of effluents. To date, substantial progress has been made in controlling and treating PS pollution, particularly at industrial sources and wastewater treatment plants. The focus of efforts has been on further reducing nitrogen and phosphorus loadings from PSs. These additional improvements need to be made in urban areas; however, these measures are costly, and as a result, more attention is being directed toward reducing non-point sources of pollution, including those associated with agriculture. Given the progress that has been made in recent years to control and treat PS pollution, non-point source pollution sources now contribute to the majority of water quality problems (United States Geological Survey 1999).

Non-point source (NPS) pollution involves the deposition and movement of contaminants, including fertilizers and pesticides from agriculture and residential areas; nutrients from livestock and pet wastes; and septic systems; persistent bioaccumulative toxins and other toxins from impervious surfaces; erosion and siltation of streams from land disturbances associated with development, silviculture, and agriculture; and atmospheric deposition of nitrogen and other contaminants from automobiles, power plants, and other industrial sources onto land or directly into water. Activities associated with urban land uses are also a substantive source of NPS pollution to receiving waters. Due to the diversity of sources and complexities inherent in interactions between land use and hydrology, NPS pollution is more difficult to control than PS pollution. The magnitude of NPS pollution impacts varies hour to hour and season to season. In the USA, NPS programs are developed based on design and implementation of preventative water resource management practices incorporating water management technologies that recognize competing resource needs. In the USA, according to studies conducted by USGS for the National Water Quality Assessment (NAWQA), over 70 associated with diffuse NPSs of pollution from agricultural land, urban land development, forest harvesting, and the atmosphere (United States Geological Survey 2015).

To date, efforts to control and treat PS pollution have largely been the result of regulation at the federal level in the USA. Conversely, efforts to control and treat NPS pollution have largely been voluntary and subsidized through federal and state cost-share programs, such as the Environmental Quality Incentive Program, Conservation Reserve Program and Wetlands Reserve Program administered by the US Department of Agriculture, Natural Resources Conservation Service (USDA, NRCS). While these programs have provided important incentives, there is increasing public pressure to regulate NPS pollution through such mechanisms as Total Maximum Daily Loads (TMDLs), administered by the EPA or similar state-led regulatory programs. TMDLs are intended to address the needs of impaired water bodies by establishing standards and allocating pollutant loads among PSs and NPSs in a watershed. At the same time, a few states have enacted 
laws to regulate NPS pollution. These regulations have largely come about as the result of regional problems, such as nitrate contamination of groundwater in Nebraska, animal waste problems in North Carolina and Maryland, and pesticide contamination of groundwater in California and Wisconsin. Most state programs target specific pollutants or operations, and only a few deal with agricultural NPS pollution in a comprehensive manner (United States Department of Agriculture 2003).

Since 1991, USGS scientists with the NAWQA program have been collecting and analyzing data and information in more than 50 major river basins and aquifers across the USA. The goal is to develop long-term consistent and comparable information on streams, groundwater, and aquatic ecosystems to support sound management and policy decisions. This work has demonstrated that water quality conditions and aquatic health reflect a complex combination of land and chemical use, land-management practices, population density, and natural features, such as soils, geology, hydrology, and climate. Further, this work found that seasonal patterns in water quality exist and these patterns mainly reflect the timing and amount of chemical use, the frequency and magnitude of runoff from rainstorms or snowmelt, and specific land-management practices, such as irrigation and tile drainage. While no single land use is completely responsible for NPS pollution, agriculture is considered as a leading source of impairments to the streams, rivers, and lakes according to the National Water Quality Inventory (United States Environmental Protection Agency 2002). NAWQA studies indicate that both nitrogen and phosphorus levels in nearly 80 watersheds sampled are excessive and contribute to algae growth. The highest concentrations of nutrients and pesticides were found to coincide with the application of chemicals during the spring and summer in most agricultural watersheds. Other key water quality findings in studied agricultural watersheds include:

- Some of the highest levels of nitrogen occur in streams and groundwater in agricultural areas.

- Pesticides - primarily herbicides—are found frequently in agricultural streams and shallow groundwater, and they commonly occur in mixtures. At least, one pesticide was found in more than $95 \%$ of sampled streams.

- Insecticides that were used in the past still persist in agricultural streams and sediment. For example, DDT use was restricted in the 1970s and 1980s, but in more than $20 \%$ of the sampled agricultural sites, one or more sediment quality guideline was exceeded.

Advances in both point and NPS water management science and technology are required and need to be integrated into water policy in order to further progress in achieving water quality goals within the US rural and urban landscapes. According to USGS's survey of states, 40 contaminated for basic uses including fishing and swimming. It is important to note that this work, while important, only involves a small percentage of US waters. The findings related to both agriculture-dominated watersheds and urban-dominated watersheds demonstrate that more work remains to be done to minimize water qualityrelated impacts associated with agricultural activities, as well as urban land-management activities. In general, the sources of water pollution have not necessarily changed over time, although the magnitude of their impact on water quality has been reduced in some areas due to actions taken in the last several decades. It may take decades to actually see marked improvements in water quality associated with implementation of most water science and technology innovations.

The complicated water management issues today require a holistic watershed approach involving all interested people. Such an approach spurs innovation and increases the amount of water management alternatives available to manage water problems. The American public is increasingly interested in pursuing regional solutions to waterbased problems. For example, in the USA, the Clean Water Action Plan (CWAP) was developed in 1998 jointly by the USDA and EPA in conjunction with other federal agencies and the public, as directed by the Vice President of the USA (United States Environmental Protection Agency 1998). In fact, the CWAP was developed to commemorate the 25th anniversary of the Clean Water Act and was intended to serve as a comprehensive plan that would help revitalize the nation's commitment to water resources. Key actions described in the CWAP include focus on achieving cleaner water by strengthening public health protections, targeting watershed protection efforts, and providing communities with new resources to control polluted runoff and enhance natural resource stewardship. The plan specifically identified needs to control polluted runoff, including the development of a national strategy to minimize water quality impacts associated with animal feeding operations, allocation of addition funds to curb polluted runoff and help implement watershed restoration action strategies, development of new stormwater management controls. Products such as the CWAP have documented this interest and the "need for building watershed partnerships for realizing the vision of healthy watersheds across the nation." Moreover, the CWAP argues that by identifying watersheds that are in need of restoration actions, including water quality improvements will likely result in citizen commitment to implementation of water pollution control and natural resource measures. 


\section{Integrating innovative water management science and technology into innovative water policy: challenges and potential solutions}

The challenge to integrate innovative water management science and technology into innovative water policy to facilitate efficient and effective use of water exists in many countries, including the USA and Canada. Comparisons of these challenges have aided evaluation and identification of issues necessary to overcome. Also, it will help identify potential mechanisms to improve the integration of innovative water management science and technology into water policy and facilitate practical use of it.

\subsection{Knowing the state of water management science and technology}

It is difficult for policy makers to keep up with science and technology relating to water management. The depth and breadth of water management science and technology are daunting. Further, more research demands are being placed on available funds. Therefore, there simply is not enough time for policy and decision makers, or their staffs, to be intimately familiar with the latest research findings and technology advancements. The solution is not a matter of posting more water management information on the Web-people simply do not have the luxury of the time needed to review and study what is available.

Policy makers and decision makers must rely on others to provide them with the most recent and best science and technology in water management on which to base their decisions or develop innovative policy that benefits the economy and environment. More importance and resources need to be given to activities, institutions and personnel that bring water scientists together with policy and decision makers (or with the staff with which they rely) in order to integrate high-quality science and technology into water management. For example, staffers of policy or decision makers need to be given work time and education opportunities to keep their knowledge base current.

\subsection{Improving incentives for water management technology use in watershed management}

Within the USA and Canada, over approximately the past 15 years, there has been an increased emphasis to implement water management strategies, not based on political boundaries, as was predominantly conducted in the past, but based on watersheds as the boundary conditions to which water flow is confined within a particular hydrologic unit. For example, in December 2002, the EPA issued a policy memorandum entitled Committing the EPA's Office of Water to Advance the Watershed Approach (Office of Water 2002). Another example is the ongoing national and regional digital mapping efforts in the USA and Canada that are now focused on watershed-based mapping.

At the same time within these countries there has been increased emphasis in other sectors to participate in voluntary watershed management and stewardship activities that provide positive environmental benefits. Local communities, organizations or governments are awarded federal or state grants to implement watershed water management planning, including implementing water management technology. Efforts to maintain the traditional non-voluntary, regulatory approach are moving toward issuing permits based on a consideration of watersheds and watershed boundaries. In January 2003, EPA's Office of Water issued their Watershed-Based National Pollution Discharge Elimination System Permitting Policy Statement (Office of Water 2003) and in 2004 issued WatershedBased NPDES Permitting Implementing Guidance (Office of Water 2004). Permits issued under NPDES are starting to be issued based on watershed-loading limits as permit conditions that cannot be exceeded, and all permit dischargers within the watershed are responsible for attainment. Additionally, any load reductions at a permitted facility beyond that required to be reduced by the permit may be traded to someone else within the watershed for monetary gains. A farmer located in the watershed can implement agricultural water management technology to reduce pollution loads for trading. This has facilitated the formation and operation of water quality credit trading markets within the USA in the last decades and is serving as an important incentive for people to participate in watershed stewardship that have not otherwise participated in such activities (United States Department of Agriculture 2011).

Market-based environmental stewardship, also called environmental credit trading, is mechanisms for efficiently allocating pollution reductions among different pollution sources with different marginal control costs. Market-based environmental stewardship approaches provide flexibility to undertake actions that have the lowest cost. These market-based approaches have been shown to result in more cost-effective achievement of natural resource conservation and environmental goals compared to traditional command and control approaches.

Over the past decades, a number of initiatives undertaken by the administration have provided an impetus to facilitate environmental credit trading. These initiatives include the Climate Change Strategy (February 2002) that prescribed greenhouse gas (GHG) reduction goals and specified a role for USDA, and the EPA's Water Quality Policy (January 2003), which seeks to stimulate the adoption of market-based mechanisms to improve water quality 
nationwide. The potential for market-based solutions to achieve conservation goals was acknowledged in the USDA's Food and Agriculture Policy: Taking Stock for the New Century (September 2001) (United States Department of Agriculture 2001). Specifically, it was noted that a "comprehensive system of incentives could facilitate and accommodate emerging private markets for farm- and forest-based environmental goods and services." Environmental credit trading offers USDA unique opportunities to proactively increase environmental outputs, while reducing implementation costs.

Continued effort and resources are needed to develop digital watershed mapping at more refined scales and electronic environmental market registries and continue to develop watershed management policy and tools necessary to promote incentives to further advance watershed management and stewardship among the public. Such tools may focus on the developing "market structure," which refers to a market's standards for obtaining information and exchanging rights (Woodward 2002) or market framework, the infrastructure, regulations, and processes that guide the program operation. Tool development to implement watershed-based water credit trading markets requires financial investments. For example, such tool establishment in three different projects within the USA required funding of \$200,000 for the Lake Dillon, Colorado Project, $\$ 450,000$ for the Lower Boise Idaho Project, and $\$ 2,000,000$ for the Tar Pamlico, North Carolina Project, much of this funding coming from federal grants. To support its trading policy, the EPA has provided $\$ 800,000$ to fund 11 pilot water quality trading programs nationwide focused mainly on PS to NPS pollution credit trading in 2002 (United States Environmental Protection Agency 2003).

Policies pertaining to permits required for water pollution discharges should be developed based on watershed pollution loadings and allocations, rather than individual facility loadings to improve both cost-effectiveness and water quality. The current state of water management technology, including monitoring technology, enables this to occur. For example, in the USA and Canada, as well as many other countries, real-time water quality monitoring is being conducted for a variety of water chemical constituents and can be incorporated into benefit quantification and pollution load allocation associated with watershedbased water quality credit trading markets.

Urban and agricultural policy incorporating water management technology should focus on watershed stewardship and management based on financial incentives to further enhance participation from more watershed stakeholders who have not shown an interest to participate in such activities otherwise. For example, policies should be developed to provide incentives to those who implement non-publicly funded best management practices (BMPs) to reduce water pollution loadings within a watershed beyond an allocated level by allowing them sell such load reductions to other watershed stakeholders. This spurs innovation and facilitates use of new, innovative water management technologies, while at the same time increases public awareness and interest in water management science and technology.

\subsection{Benefit quantification}

In the USA, beginning with the Clinton Administration, there has been a growing push to review federal programs to ensure that federal investments are targeted to perform or achieve specific results. This "accountability" movement has continued to gain momentum over time, and current efforts are now focused on developing performance measures by which programs can be evaluated. The underlying expectation of these accountability initiatives is that investments in water management science and technology and programs are expected to exceed the costs. A driving force in the accountability effort is the need to control the size of the federal budget and target investments wisely.

In many cases, it is difficult to accurately quantify environmental benefits or gains of different water management technologies as applied on-site. As funding has become more limited and public interest to reduce water pollution in the USA has increased over the past decade, there has been more pressure to quantify environmental benefits associated with such technologies to ensure US public investments are worth the costs and, as such, are justified (United States Environmental Protection Agency 2008). This has resulted in advances in environmental benefits quantification, as well as quantification of the associated uncertainty, so they can be considered in the decision making and public funding or permitting processes. However, more research and development of devices, models, and methods to measure or estimate such benefits and their field testing is needed. For example, there is a scientific need to develop performance indicators that are measurable (quantifiable) and accurately reflect expected outcomes with some known degree of confidence. These measures must also be usable-that is not overly complex - as they may be used to assess trade-offs among natural resources concerns or support programmatic decisions. Further, performance measures must be comparable; there should not be so many performance measures that expected outcomes cannot be easily understood by decision makers and/or the public.

Increased research, development and field testing of devices, models, and methods to quantify (measure or estimate) water management practice, and environmental 
benefits are needed, so they may be incorporated into watershed management and permitting strategies, including watershed water quality and quantity credit trading markets. For example, watershed-based permitting policy should incorporate a range of potential environmental benefits based on their certainty and develop watershedbased water markets where part of their worth is determined based on how the benefits were quantified (i.e., associated certainty values); the more certain the method of quantification, the more the benefits would be worth on the watershed-based water market. In this case, benefits that are actually measured would be worth more than those that are estimated or based on empirical relationships. This approach is used in the Boise, Idaho, water quality credit trading program for phosphorous.

Increased training opportunities and funding are needed to improve knowledge of the latest advances in water management technology and incorporation into watershed management policy development, such as in the operation of watershed-based water quality markets.

\subsection{Defining and managing uncertainty}

When a water management technology such as a water quality BMP or control technology is being considered and implemented, uncertainty associated with its efficiency and effectiveness exists at some level. For example, there is uncertainty in estimating or measuring BMP pollution load reductions associated with urban, as well as agriculture BMPs. Additionally, there is uncertainty in estimating or measuring baseline pollution loads on a water body.

The US federal water management policies have just begun to require BMP uncertainty quantification and its consideration in funding decisions. For example, in 2003 in response to the interest of the Administration to have a better understanding of expected environmental outcomes associated with federal program investments (both regulatory and incentive-based programs), the NRCS undertook an effort to more accurately determine the environmental outcomes of conservation practices. This effort, formally known as the Conservation Effects Assessment Project (CEAP) (United States Department of Agriculture 2003), is a multi-agency effort led by NCRS intended to assess the effects of conservation practices implemented through NRCS conservation programs, including water quality improvements, and estimate benefits for five primary resource concerns. Three major agricultural land uses (cropland, grazing land, and wetlands) are being assessed as part of this work. The results of this work are intended to inform and support conservation-related policy discussions and program implementation.

Continued efforts and resources are needed to incorporate uncertainty analysis in water management policy development. Further research is needed, as well as training and knowledge exchange opportunities between scientist and policy/decision makers. Improved efforts to identify water management technology uncertainty and incorporate management mechanisms within water management policies are also needed.

\subsection{Guiding principle to water resource sustainability}

The fundamental underlying principle of water resources management should be the emphasis of conservation used in a series of sequential levels to maintain water resources sustainability. First, adverse impacts on water resources should be avoided to the maximum extent possible. Once this has been thoroughly explored, then adverse impact minimization should be conducted to the maximum extent possible. Finally, once all practicable steps are explored to minimize adverse impacts, then mitigation or offsets should be provided to compensate for adverse water resource impacts resulting from a proposed action. Economic and environmental benefits and costs, project logistics and limits of watershed management technology are some factors that should be considered in determining practicability of these sequenced steps. Such an approach facilitates use of water management technology to avoid, minimize, and mitigate adverse environmental impacts, and benefits both the economy and environment, and supports water resource sustainability. Generally, the more avoidance, minimization and mitigation needed, the more water management technology is needed-a direct relationship exists. For example in the USA, implementing regulations under the Clean Water Act, Section 404 regulating the wastewater discharge into wetlands or waterways uses this sustainability principle. This principle was not widely accepted in the USA until the early 1990s and still leads to much water resource trade-off debate.

A question that must be addressed is "what is the minimum level of adverse impact that requires mitigation for any specific project?" For example, within the USA, CWA section 404 program, mitigation is usually required for more than minimal adverse impacts. Generally, the greater the demand for mitigation, the more this will spur innovative water management technologies development and facilitate its integration in practical use. Innovation is required in project design to avoid and minimize potential water resources impacts as well.

Increasingly, however, potential adverse impacts are viewed on both a project footprint scale and a watershed scale through a consideration of cumulative impacts. This also leads to the question how cumulative adverse water resource impacts (minor impacts resulting from single projects, but when added together have greater adverse 
impacts) are quantified, accounted for, managed, and mitigated. The need to assess cumulative impacts has and is expected to continue to facilitate water management technology use and ultimately integration into water management policy. For example, since the mid-1990s, in the CWA Section 404 program, databases, such as accounting registries, are used to account for minimal adverse impacts associated with any single project, and then, project proponents pay a fee or buy into a mitigation project located within the same watershed or same region as the proponent's project to compensate for minor adverse impacts occurring in that watershed or region. Generally, in-kind mitigation is preferred, and various water management technologies are incorporated into this in-kind mitigation.

\subsection{Incorporating adaptive management and environmental management systems into water management}

There are ways to help assure water resource gains associated with a project outweigh the adverse project impacts (i.e., each project provides for water resource sustainability) by managing the uncertainty associated with mitigation (i.e., adverse impact quantification, and successful mitigation project completion), such as applying discount factors or safety ratios. An important mechanism to manage uncertainty associated with using water management technology is adaptive management. A general adaptive management model used by many US federal agencies is plan, predict, implement, monitor, and adapt. In the USA, in last decade, adaptive management is being used as a mechanism to manage uncertainty of: quantifying water quality parameters including adverse impacts (i.e., measurement, estimation, and modeling); mitigation; and predicting future environmental conditions. For example, in 1997, the Council on Environmental Quality (CEQ) recognized that the traditional environmental management model "predict, mitigate, and implement" used in the USA and elsewhere did not account for unanticipated changes in environmental conditions, poor predictions, or more recently developed useful information. Therefore, it recommended adding "monitoring and adapting" components into an updated adaptive management model as "predict, mitigate, implement, monitor, and adapt" (Council on Environmental Quality 1997). This approach acknowledges there is uncertainty, and develops a mechanisms to manage it through advanced planning and consensus of interested people.

More and more water resources projects in the USA, Canada, and elsewhere are incorporating an adaptive management model. For example within the USA, the National Research Council issued a report in April 2004, entitled Adaptive Management for Water Resources
Project Planning (Panel on Adaptive Management for Resource Stewardship 2014). The report convened a panel of US academicians and practitioners to evaluate how adaptive management is being incorporated into large water resource projects to improve project planning and performance within the USA, and make recommendations how it might be improved. The report makes many such recommendations.

Another example within the water management technology area is the EPA encouraging States to develop TMDLs for a variety of water chemical constituents or parameters, such as various phosphorous, and nitrogen chemical constituents, sediment, and water temperature. Working with EPA, some states are developing watershedbased NPDES permits. This is an adaptive management approach that incorporates new, innovative water management technology, in that there is more flexibility given to compliance time periods and load restrictions at any given discharger. This flexibility allows dischargers to implement more recently developed water management technologies that have yet to undergo extensive, performance field testing (as opposed to laboratory testing), as dischargers monitor and can now adapt to technology performance on a watershed basis, instead of a facility basis. For example, a wastewater treatment facility can cost-effectively select and implement a newly developed, laboratory tested, nitrogen or phosphorous reduction process at the facility, if they have to achieve a certain loading or load reduction every week, rather than daily. Similarly, they can cost-effectively purchase credits from other facilities, organizations or farmers in the watershed who have implemented BMPs to reduce phosphorous or nitrogen loadings, and are selling credits through the local watershed $\mathrm{N}$ or $\mathrm{P}$ reduction market, if their newly implemented technology has not performed as predicted. This approach adds flexibility to regulatory requirements without decreasing or compromising water quality. Such an approach also facilitates incorporation of new, innovative water management technology by adding flexibility in options available to dischargers to manage uncertainty associated with new technology. However, such approaches are only in their infancy of implementation in the USA and will require more funding, education and outreach to be more widely implemented.

There is also a movement toward integrating an adaptive management approach using Environmental Management Systems (EMSs). In 1996, the International Organization for Standardization established an EMS standard called ISO 14001 (International Standard Organisation 1996). In 2001, the President of the USA issued Executive Order 13148 entitled Greening the Government through Leadership in Environmental Management (US Government Publishing Office 2000). It calls for federal agencies to 
implement EMSs at all facilities operated by agencies by the end of December 2005. Several US federal agencies, as well as many private companies are implementing and operating EMSs, which use adaptive management. Additionally, in September 2003, an US interagency task force that evaluated and made recommendation to the CEQ on how to modernize the National Environmental Policy Act (NEPA) process and make it more efficient and effective found that incorporating adaptive management and EMSs into the NEPA was in its infancy, and showed promise as a mechanism to help improve the effectiveness and efficiency of NEPA. Several recommendations within the report request CEQ to establish an interagency task force to further evaluate how adaptive management and EMSs can be incorporated into the NEPA process (Council on Environmental Quality 2003).

Although other EMS models are available, most agencies are incorporating EMS models that include the following components (Council on Environmental Quality 2003):

- Commitment to continual improvement, pollution prevention, and compliance with relevant environmental legislation and regulations.

- Procedures to identify a facility's environmental impacts, legal, and other responsibilities, and environmental management programs

- System implementation and operation

- Checking and corrective actions

- Management reviews to address changing conditions and information.

\section{Conclusions}

Good quality water is a limited resource in the USA and many nations. Advances in water management science and technology can enable us to make better use of this precious resource. To date, the application of water management science and technology advances has not been adequately incorporated into water policy. As there are increasing demands placed on the water available, there will be an increased need to integrate the science and technology into innovative water policy. Challenges to such integration exist and include the need to educate decision makers, lack of needed incentives, limited benefit quantification methods, uncertainty in technology performance measurement and estimation, the need for comprehensive guiding principles such as sustainability, and lack of broad-scale application of techniques such as adaptive management and EMSs. There is a compelling need to continue to make advances in the water management science and technology arena; however, there is a commensurate need to educate decision makers and stakeholders about the potential benefits derived by the application of such advances. The reality is that there is a substantive knowledge gap that exists between those who are making technical advances in the water management arena and those who are formulating policies and making decisions. The problem is twofold-researchers have not effectively and consistently described the importance of their work in ways that could compel broad-scale policy changes and decision makers have limited time to commit to full-scale study of potential solutions to recurring water problems. Without substantive effort, this knowledge gap will widen as increasing demands are being placed on decision makers and their staffs without commensurate increases in funding levels. The net effect will be delays in the realization of benefits from the application of technical advances being made today caused by unnecessary implementation delays.

We live in exciting times and important advances are being made in the water management science and technology field. We all need to make the time to work together to create forums through which we can share the results of our technical work with one another, while at the same time, informing decision makers and stakeholders of potential applications.

\section{References}

Council on Environmental Quality (1997) The National environmental policy act: a study of its effectiveness after twenty-five years. Executive Office of the President, Washington, D.C

Council on Environmental Quality (2003) Modernizing NEPA implementation. Executive Office of the President, Washington, D.C

General Accounting Office (2003) Freshwater supply: states? View of how federal agencies could help them meet the challenges of expected shortages. General Accounting Office, Washington, D.C

International Standard Organisation (1996) ISO 14001:1996 environmental management systems. International Standard Organisation, Geneva, Switzerland

Office of Water (2002) Committing the EPA? Office of water to advance the watershed approach, United States Environmental Protection Agency, Washington, D.C

Office of Water (2003) Watershed-based npdes permitting policy statement. United States Environmental Protection Agency, Washington, D.C

Office of Water (2004) Watershed-based national pollution discharge elimination system (NPDES) permitting implementing guidance. United States Environmental Protection Agency, Washington, D.C

Panel on Adaptive Management for Resource Stewardship (2004) Adaptive management for water resources project planning. The National Academies Press, Washington, D.C

Ribaudo M, Gollehon N, Aillery M, Kaplan J, Johansson R, Agapoff J, Christensen L, Breneman V, Peters M (2003) Manure management for water quality: costs to animal feeding 
operations of applying manure nutrients to land. United States Department of Agriculture, Washington, D.C., USA

U.S Government Publishing Office (GPO) (2000) Executive Order 13148? Greening the government through leadership in environmental management, U.S. Government Publishing Office, Washington, D.C

United States Department of Agriculture (2001) Food and Agriculture policy: taking stock for the new century. United States Department of Agriculture, Washington, D.C

United States Department of Agriculture (2003) Conservation effects assessment project. United States Department of Agriculture, Washington, D.C

United States Department of Agriculture (2003) Manure management for water quality: costs to animal feeding operations of applying manure nutrients to land. United States Department of Agriculture, Washington, D.C

United States Department of Agriculture (2011) Natural resources credit trading reference. United States Department of Agriculture, Washington, D.C

United States Environmental Protection Agency (1998) Clean water action plan: restoring and protecting America's waters. United States Environmental Protection Agency, Washington, D.C

United States Environmental Protection Agency (2002) National water quality inventory: 2000 report to congress. United States Environmental Protection Agency, Washington, D.C
United States Environmental Protection Agency (2003) EPA Releases Innovative Approach to Cleaner Water: 11 Pilots Receiving More than $\$ 800,000$ in Funding, Newsroom, United States Environmental Protection Agency, Washington, D.C. http:// yosemite.epa.gov/opa/admpress.nsf/b1ab9f485b098972852562e 7004dc686/7f1b0616de4dc2a285256cad006a60a7?OpenDocum ent

United States Environmental Protection Agency (2003) History of the clean water act. United States Environmental Protection Agency, Washington, D.C

United States Environmental Protection Agency (2008) EPA water quality trading evaluation. United States Environmental Protection Agency, Washington, D.C

United States Geological Survey (1999) The quality of our Nations? Waters nutrients and pesticides. United States Geological Survey, Washington, D.C

United States Geological Survey (2015) National water-quality assessment (NAWQA) program. United States Geological Survey, Washington, D.C

Woodward R (2002) The structure and practice of water-quality trading markets. Journal of the American Water Resources Association 38:967-979 